\title{
39
}

\section{La Periodización de la Historia Contemporánea de México}

\author{
EUGENIA MEYER \\ Instituto Nacional de Antropología e Historia
}

La periodización del acontecer histórico aparece como una tarea constante e ineludible en la labor del historiador, cualesquiera sean sus intereses específicos. Tarea que, por otra parte, puede originarse en la premisa de que es el tiempo, el elemento condicionador de la Historia, ${ }^{1}$ tanto en su carácter de persistencia como en el cambio. Es el tiempo el que permite al historiador delimitar, agrupar, separar o unificar una serie de hechos y generar entonces su propia actividad creadora como historiador.

El concepto de tiempo histórico puede variar. Puede alcanzar el extremo de la visión hegeliana que acepta que el tiempo es el elemento condicionador de la Historia, pero en su carácter de "continuidad homogénea," simplificando la labor histórica a la realización de cortes apropiados de ese tiempo, y entonces poder así estudiar el proceso de las ideas. En el otro extremo, puede entenderse la historia como lo hace el marxismo, donde el criterio de periodización se estructura en base a "la evolución dialéctica de la economía,"2 puesto que el motor de la Historia lo constituyen las fuerzas sociales comprometidas en la lucha de clases.

${ }^{1}$ Cf. John Womack, Jr., "Mexican Historiography. 1959-1969," in Investigaciones Contemporáneas sobre Historia de México: Memorias de la tercera reunión de historiadores mexicanos y norteamericanos, Oaxtepec, Morelos 4.7 de noviembre de 1969, México: Universidad Nacional Autónoma de México,'El Colegio de México, Austin, University of Texas, 1971, pp. 478-492.

${ }^{2}$ Marta Harnecker, Los conceptos elementales del materialismo histórico, México: Siglo XXI, Editores, 1972, p. 222. 
De una u otra forma, el historiador se ve obligado a dividir el tiempo histórico antes de realizar cualquier investigación, tomando en cuenta ya sea los intereses políticos, los cambios socio-económicos, etc. Esto es: en su propósito de comprender al hombre, debe enmarcarlo en el tiempo y en el espacio.

Es indudable también, que cualquier periodización, global o parcial, surge como resultado de la capacidad y las cualidades inventivas del historiador, quien en su intento por darle un contexto lógico a lo que sabe, a lo que averiguó, investigó y a lo que supone, deberá aportar también una buena porción de su propia capacidad especulativa (aspecto que, por cierto, puede marcar la sutil barrera entre la historia y la novela histórica).

Cuando nos referimos a la periodización, hay que diferenciar también entre la que pretende ser general y la que busca en definitiva la particularidad. En el primer caso, puede efectuarse ante dos perspectivas, a saber: la del compendio, simple relato cronológico, o cuando se pretende hacer una síntesis en donde el propósito fundamental será el sentido que se le puede dar a los hechos dentro de un proceso histórico.

En el caso de realizar una investigación particular, la periodización estará sujeta a los intereses de la etapa que se pretende trabajar. No olvidemos aquí que la periodización aparece también condicionada por la vanidad y la ambición del historiador; ésto es: qué tanto sabe y qué tanto pretende o supone podrá abarcar en su investigación.

Hasta hoy, en la periodización empleada tradicionalmente en la historia de México, subsiste el viejo concepto de la demarcación - en ocasiones exageradamente rígida - basada en los cambios de control de poder: período prehispánico, colonial independiente y esa monumental vaguedad definida como "período nacional."

Ello, claro, lleva a suponer que la periodización global de la historia de México podría ser revisada tomando en cuenta las categorías históricas inconscientes. El concepto, por ejemplo, del periodo independiente e historia nacional que va de 1821-1854, luego de $1854-1876$ y de 1876-1910, podría ofrecer cambios.

Podría incluso pensarse en otras posibilidades para el concepto del porfiriato, como régimen de orden y progreso constituido desde 1877 hasta 1914, pensando quizá que fue entonces cuando, con la caída de Huerta, se rompió el viejo orden.

Parte del problema que implica toda la periodización, está sujeto también a la importancia y relevancia que se le dé al momento presente en función del pasado.

Para intentar una nueva periodización, habría que proponerse antes una labor revisionista, partiendo de una serie de conceptos o atributos que dan su carácter a la historiografía contemporánea sobre México. 
Esta historiografía, especialmente la que se ha dado en llamar de "la Revolución Mexicana," adolece de intenciones políticas, de partidismos o banderías. Es ante todo justificatoria, poco profesional especialmente la abundante producción nacional sobre el periodo posterior inmediato a la lucha armada. Sigue siendo por sobre todo, una historia que pretende el culto a la personalidad; institucionalizada y oficialista. Las más de las veces es una historia carente de libertad creadora y hasta expresiva. Subsisten los temas tabús, los periodos en "tinieblas," y los personajes intocables unos e ignorados otros.

Seguimos ocupados en una historia que cultiva el mito al héroe. Una historia que no usa, sino abusa del maniqueismo como elemento determinante de su existencia. Es una historia de caudillos, traidores o patriotas, en donde el ente histórico, México, sigue apareciendo como imperturbable, impasivo, al que le acontece la historia.

Luego de la Revolución y la reestructuración del poder político de México, la historiografía mexicanista empezará a buscar otros cauces. Tanto en la nacional como en la extranjera, se presenta un fenómeno común muy sintomático: para los historiadores contemporáneos, generalmente el concepto de historia de la Revolución Mexicana arranca desde los albores del presente siglo, hasta bien entrada su cuarta década. Es decir, los historiadores han tomado el concepto de revolución como elemento temático generalizado para identificar la historia mexicana del siglo XX. Parecería existir, en todos los niveles un propósito unánime e impersonal, un empeño desmedido por mantener más presente que viva la idea de revolución por todos los medios retóricos, sin que los historiadores hayan podido librarse del contagio.

Una enorme cantidad de historias elaboradas con intenciones de síntesis se detienen en los años cuarenta. Se diría que el estudiar e incluso lanzarse al análisis de épocas más recientes, implica riesgos que pocos historiadores han querido tomar hasta la fecha. Surge, claro, la vieja discusión de cuánto, dentro de un concepto rígido de cronología, le corresponde analizar al historiador, cuánto al sociólogo, cuánto al antropólogo social y cuánto al politólogo.

La historia contemporánea de México, por otra parte, parece más bien oscilar, ser un péndulo que se va paseando, de manera altamente enajenada, a lo largo de los diferentes sexenios gubernamentales.

Por desidia, cautela, mera pereza o comodidad, hasta hace muy poco sólo se hacían crónicas de los últimos gobiernos sin detenerse siquiera, o pretender analizar el contexto global de la historia contemporánea nacional.

Es cierto también que parte del material existente en archivos - tanto públicos como privados - que podría aclarar muchos momentos oscuros, aún permenecen cerrados, limitando significativamente la investigación. Y los que están abiertos, a veces representan carreras de obstáculos y prueba máxima a la paciencia del investigador frente al letárgico mundo del trámite burocrático oficial. 
Ante esta situación tácita, o ante la otra, muchas veces peor, de los archivos arreglados y de las hojas de servicio pulidas, cabe preguntar: ¿y para qué una nueva periodización, si las posibilidades de investigación futura habrían de partir por principio de una premisa falsa o artificial . . ?

No olvidemos aquí tampoco que el concepto de la tarea histórica, como ciencia que vive y se nutre de su desarrollo, debe ser creciente en descubrimientos; debe mostrarse siempre insatisfecha, en fin dinámica.

Es fácil criticar la periodización empleada hasta la fecha, $\mathrm{y}$ por supuesto siempre resulta mucho más cómoda la actividad de critica que la de creación. Sin embargo, lo existente, a fuerza de ser lo obviamente correcto o incorrecto, según el caso, por lo mismo que ya existe puede servirnos como punto de partida para enmendar errores, subsanar lagunas $y$, por último, para proponer cambios o nuevos criterios. De ahí que nos hayamos puesto a realizar una celerísima revisión historiográfica, sin criterio discriminatorio de nacionalidades, autores o especialidades. Tomamos algunos autores nacionales, otros extranjeros; algunos profesionales de la historia, otros cronistas, memorialistas o biógrafos aficionados. El resultado, sin duda no sorprendería a nadie. Son muy pocos los casos en que se han atrevido realmente a romper con lo que nosotros denominamos la periodización oficial.

La nuestra sigue siendo una historia de vencedores y en muy pocas ocasiones conocemos la versión de los vencidos. El problema básico y casi común en todas las obras, es el concepto de Revolución, concepto a veces romántico, del que se abusa en ocasiones, alegando todavía su visión jacobina.

Por principio de cuentas, aunque hubo algunos propósitos aislados anteriores, hasta la obra editada por Stanley Ross: Is the Mexican Revolution Dead ${ }^{3}$ se intenta ya definir la situación en que se conceptúa. $\mathrm{Y}$ así ha quedado para que se la defienda, se la rescate o en última instancia se la entierre.

Para periodizar la historia contemporánea, debemos sin duda recapitular y encarar el problema de si la Revolución continúa, ha quedado interrumpida, congelada o inconclusa. Y aquí cabe aplicar lo que el sovietólogo Deutscher dijera de la Revolución Rusa:

la revolución de ninguna manera ha llegado a su fin, aún está en movimiento, aún puede sorprendernos por sus agudos e intempestivos cambios. Aún es capaz de rediseñar toda su propia perspectiva. El terreno en que ha entrado es tal, que los historiadores o temen recorrer o deben recorrer con temor... Pero, podemos realmente hablar de una continuidad revolucionaria. Los ideólogos soviéticos insisten en decir que la continuidad revolucionaria nunca se ha interrumpido. Otros dicen que se ha preservado como una forma externa únicamente, como una concha,

${ }^{3}$ Stanley R. Ross, ed., Is the Mexican Revolution Dead? New York: Knopf, 1966. 
como un caparazón ideológico encubriendo realidades que nada tienen en común con las altas aspiraciones de $1917 .^{4}$

Es indudable que el concepto histórico de tiempo, no puede ni debe restringirse a su conceptuación empírica: un tiempo único lineal, simplemente cronológico, que conduce forzosamente a interpretaciones rígidas, como en el caso de la historia mexicana a partir de 1940.

También resulta entonces importante referirse al problema que para la periodización, vieja o nueva, significa el dilema de si la Revolución terminó, desapareció o si continúa.

Recientemente y de manera por demás manifiesta, en la obra de Adolfo Gilly ${ }^{5}$ se estructuran tres posibles enfoques de esta Revolución:

Todas las interpretaciones de la revolución mexicana (las que pretenden estar dentro del campo de la revolución, pues no nos interesan aqui las otras) pueden agruparse en tres concepciones fundamentales:

a) La concepción burguesa, compartida por el socialismo oportunista y reformista, que afirma que la revolución, desde 1910 hasta hoy es un proceso continuo, con etapas más aceleradas o más lentas pero ininterrumpidas, que va perfeccionándose y cumpliendo paulatinamente sus objetivos bajo la guía de los sucesivos gobiernos de la revolución".

b) La concepción pequeñoburguesa y del socialismo centrista, que sostiene que la revolución de 1910 fue una revolución democráticoburguesa que no logró sino parcial o muy parcialmente sus objetivos - destrucción del poder de la oligarquia terrateniente, reparto agrario y expulsión del imperialismo -, no pudo cumplir sus tareas esenciales y es un ciclo cerrado y terminado. En consecuencia es preciso hacer otra revolución que nada tiene que ver con la pasada: socialista dicen unos, antimperialista y popular otros, más preocupados por las declaraciones "revolucionarias," y por no entrar ellos mismos en contradicciones, que por la seriedad política y científica.

c) La concepción proletaria y marxista, que dice que la Revolución Mexicana es una revolución interrumpida. Con la irrupción de las masas campesinas y de la pequeñaburguesía pobre, se desarrolló inicialmente como revolución agraria y antimperialista y adquirió, en su mismo curso, un carácter empíricamente anticapitalista llevada por la iniciativa de abajo y a pesar de la dirección burguesa y

${ }^{4}$ Issac Deutscher, La revolución inconclusa: 50 años de historia soviética (1917-1967); Conferencias "George Macaulay Trevelyan" pronunciadas en la Universidad de Cambridge, 1967, México: Ediciones Era, 1967.

${ }^{5}$ Adolfo Gilly, La Revolución Interrumpida, México, 1910-1920: Una guerra campesina por la tierra y el poder, México: Ediciones El Caballito, 1972. 
pequeño burguesa dominante. En ausencia de dirección proletaria y programa obrero, debió interrumpirse dos veces: en 1919-1920 primero, en 1940 después, sin poder avanzar hacia sus conclusiones socialistas; pero, a la vez, sin que el capitalismo lograra derrotar a las masas arrebatándoles sus conquistas revolucionarias fundamentales. Es por lo tanto una revolución permanente en la conciencia y la experiencia de las masas, pero interrumpida en dos etapas históricas en el progreso objetivo de sus conquistas. Ha entrado en su tercer ascenso - que parte no de cero, sino de donde se interrumpió anteriormente - como revolución nacionalista, proletaria y socialista. $^{6}$

Es indudable que el concepto trotskista del autor, en su intento de interpretar la Revolución Mexicana como una revolución agraria, ha planteado una nueva posibilidad para situar y rescatar la imagen perdida o deteriorada de la que aparece ya como desprestigiada y vilipendiada Revolución Mexicana.

Las ideas sobre la vivencialidad de nuestra Revolución han ido variando. Al conmemorarse el medio siglo del inicio tradicional y oficialmente aceptado de 1a Revolución, el gobierno gestionó la publicación de una serie de volúmenes con el sugerente título de: México, 50 años de Revolución. ${ }^{7}$ Se pretendía, en cuatro grandes apartados, hacer un balance de la vida nacional tanto en los aspectos políticos y económicos como sociales, tratando por separado las cuestiones de cultura.

Es interesante recordar que la publicación, patrocinada por el entonces presidente de la República, Lic. Adolfo López Mateos, insiste en hablar de cincuenta años de revolución. Ello nos lleva a suponer que el gobierno acepta de hecho como fecha inicial de esta Revolución el levantamiento maderista de 1910, y que ¡aún hoy continuamos en la misma revolución!. Es decir, nuestros gobernantes - debemos suponer - se autodefinen como continuadores aunque no herederos de la Revolución.

En estos volúmenes se observa claramente cómo los colaboradores hablan de que hace cincuenta años se inició el movimiento revolucionario, y que de allí derivó el "régimen de la Revolución," dando por supuesto, que éste ha sido uno, indivisible durante las últimas cinco décadas.

Ya Stanley Ross decía que no era una mera cuestión de semántica el hablar de la Revolución como viva o muerta, sino que esta implicaba una serie de conceptos relativos a la idea histórica de Revolución. ${ }^{8}$

En el caso de los mexicanos, parece ser que el malestar o malentendido con

\footnotetext{
${ }^{6}$ Ibid., pp. 397-398.

${ }^{7} 4$ vols., México: Fondo de Cultura Económica, 1962.

${ }^{8}$ Cf. Ross, Is the Mexican Revolution Dead? Introduction.
} 
respecto a la delimitación de la Revolución se debe a un problema persistente a lo largo de nuestra historia: el deseo desmedido de nuestro pueblo de vivir varios tiempos históricos a la vez, simultáneamente, e incluso vivir en el pasado, sin demarcar los cambios ni aceptar la posible terminación de etapas históricas. Esto es, existe sin duda una negativa a desembarazarse del pasado.

Los participantes ideológicos o militantes de la Revolución presentan su propia visión y definición. Por ejemplo Roque Estrada dividia la Revolución en cuatro etapas:

I: Elaboración de necesidades individuales y sociales, no satisfechas, ya sea por impedirlo los propios factores constitutivos de la sociedad o del organismo gubernativo. II: Concentración de esas necesidades en un poderoso núcleo que fatal e inexorablemente reclama una transformación político-social. III: Destrucción de los obstáculos, por medio de las armas, cuando la fuerza social no encuentra otra vía; provocando asi una insurrección. IV: Reconstrucción caracterizada por la labor gubernativa, tendiente a realizar las lógicas promesas insurreccionales. ${ }^{9}$

Luis Cabrera por su parte, consideraba que los años de 1906 a 1910 eran los pródromos de la Revolución y no debían confundirse con ella siendo simplemente síntomas de malestar social e intentos legales más o menos utópicos planteados para resolver ese malestar; de 1910-1916, período de destrucción o lucha; luego de 1914-1923 período de legislación, conocimiento y reconocimiento del régimen revolucionario. ${ }^{10}$

Para Cabrera, la Revolución había terminado el 30 de abril de 1917, al instaurarse el gobierno constitucional. Pero, "teniendo en cuenta las resistencias que Carranza encontró todavía para gobernar conforme a los preceptos de la Constitución de 1917, las diversas insurrecciones o intentos de restauración que tuvo que vencer, y sobre todo la renuncia de los paises a reconocer nuestra Constitución, tendremos que llegar a la conclusión de que la Revolución no terminó propiamente hasta el año de 1923, cuando los Estados Unidos, en vías de transacción y porque les convenía, admitieron expresamente la vigencia de nuestra Revolución." ${ }^{11}$ Esto hace suponer que fue un factor de tipo externo el que definió la perduración y por ende la periodización de la Revolución.

En otro género de producción histórica parece ser que en las síntesis, como se advertía en páginas anteriores, hay un propósito por encuadrar dentro de un todo global a la Revolución Mexicana, que iría entonces de 1910 a 1960.

${ }^{9}$ Roque Estrada, La Revolución y Francisco I. Madero: Primera, segunda y tercera etapas, Guadalajara: Imprenta Americana, 1912, pp. 11-12.

${ }^{10}$ Luis Cabrera, "La Revolución Mexicana," El Porvenir (Monterrey), 22 de noviembre de 1950 .

${ }^{11}$ Ibid. 
Generalmente estos trabajos de sintesis históricas, por premura, economía de páginas o mero agotamiento, tanto de quien escribe como supuestamente del lector, lo abrevian y archiresumen todo al máximo, haciendo que el siglo XX aparezca como el "Siglo de la Revolución.". 12

En otros casos, como el de José Valadés en su Historia del Pueblo de México desde sus origenes hasta nuestros dias, ${ }^{13}$ se sitúa cronológicamente la Revolución, como la porción de la historia de México que ocupa los años comprendidos entre 1910 a 1917 , definiendo luego el periodo de 1920 a 1932 como el de un "Estado guerrero" y completando el resto con el llamado "Estado burocrático." Valadés insiste en considerar que hay un fin de la Revolución, puesto que "la doctrina del pueblo: democracia, soberanía, sufragio, libertad de 1910, quedó hecha escombros, en el transcurso de medio siglo, por la fuerza del Estado, Orden, Paz, Continuidad, Autoridad - que es el capítulo de la trascendencia histórica a donde ha llevado a México, el régimen de la evolución nacional de los pueblos." 14

Luego, claro está, podemos referirnos a las obras históricas que pretenden hacer síntesis de la Revolución Mexicana, ofreciendo entonces una visión global de la Revolución con una increíble duración de tres décadas, y en ciertos casos hasta de cuatro.

Vera Estañol, testigo presencial de la historia contemporánea y uno de los más significativos representantes de esa corriente de historiadores que bien podriamos definir como apologistas, se muestra defensor de la periodización tradicionalmente aceptada y así se refiere a los orígenes porfiristas que le permiten justificar la Revolución. Hace un repaso de "la revolución maderista," luego del duunvirato provisional, de la seudodemocracia maderista y del gobierno de facto. Viene luego la Constitución de Querétaro y los gobiernos neoconstitucionales, siempre en la presuposición de que la Revolución incluye los gobiernos de Obregón, Calles, el Maximato y Cárdenas, llegando hasta Ruiz Cortines. ${ }^{15}$

Sin embargo, Vera Estañol señala que la Revolución concluye tácitamente en 1920 con el gobierno de Carranza, y que los gobiernos que le sucedieron fueron parte de la familia revolucionaria. Esto explicaria con claridad el hecho de que su historia deje de serlo a partir de 1920, para convertirse en

${ }^{12}$ Véase como ejemplos: Alfonso Teja Zabre, Historia de México: Una moderna interpretación, México: Imprenta de la Secretaría de Relaciones Exteriores, 1935, y Wigberto Jiménez Moreno y Alfonso García Ruí, Historia de México, México: INAH, 1962.

${ }^{13}$ José Valadés, Historia del Pueblo de México desde sus origenes hasta nuestros días, 3 vols., México: Editores Mexicanos Unidos, 1967.

14 Ibid., p. 413.

${ }^{15}$ Jorge Vera Estañol, La Revolución Mexicana: Origenes y resultados, México: Editorial Porrúa, 1957. 
una mera relación de los períodos gubernamentales. De esta manera, quizá no se compromete ni peligra la imagen tan arduamente defendida por la historia institucional, insistiendo en referirse sin analizar a los gobiernos posteriores a 1917, para evitar así cualquier tipo de compromiso o componenda que pudiera conducir a juicios evaluativos de la Revolución en cuestión. Así pues, surge una corriente que acepta un détente, en 1917 o quizá un poco después, en 1920, como es el caso de los libros auspiciados por el Instituto de Estudios Históricos de la Revolución Mexicana.

Surgen también autores que, como Silva Herzog, consideran (igual que lo hiciera años atrás el propio Cabrera) a la Revolución Mexicana como concluída, con la llegada de Carranza a la presidencia en mayo de 1917. Sin embargo, a diferencia de muchos de sus contemporáneos, Silva Herzog no acepta el movimiento revolucionario como iniciado en noviembre de 1910, pues reconoce otros brotes anteriores al maderismo. Resulta interesante señalar que el propio autor habla ya de la Revolución Mexicana como hecho histórico del pasado. ${ }^{16}$

En otros casos de síntesis de la historia revolucionaria, como la de José Mancisidor, ${ }^{17}$ aparecen también los antecedentes a la lucha y se advierte que el proceso concluye en 1920. Este autor estudia los gobiernos que le sucedieron, a partir de Obregón, como pertenecientes a una época postrevolucionaria. Aún así, no deja de apreciar la Revolución como una institución nacional.

Manuel González Ramírez publica en 1960 sus tres volúmenes de $L a$ Revolución Social de México, ${ }^{18}$ advirtiendo que la suya pretende ser una obra histórica "que interprete a la Revolución Mexicana, que tuvo su desarrollo durante la primera mitad del siglo XX." ${ }^{19}$ Sin embargo su relato concluye con la muerte de Carranza en 1920. Concede entonces que el periodo inmediato poterior fue de reconstrucción.

Otro de los problemas que se observa en la historiografía sobre la Revolución Mexicana, es el desglose de dicha revolución en varias "diferentes revoluciones." Asi se ha hecho desde la tajante diferenciación de Cabrera entre "La Revolución de Entonces y la de Ahora." ${ }^{20}$ con su crítica y condenación del régimen cardenista por intentar ser el continuador de la

${ }^{16}$ Cf. Jesús Silva Herzog, "México a 50 años de su Revolución," Cuadernos Americanos, 132 (1963), pp. 13-14.

${ }^{17}$ José Mancisidor, La Revolución Mexicana, México: Ediciones El Gusano de Luz, 1958.

${ }^{18}$ Manuel González Ramírez, La Revolución Social de México, 3 vols., México: Fondo de Cultura Económica, 1960.

${ }^{19}$ Ibid., 1, ix.

${ }^{20}$ Luis Cabrera, La Revolución de Entonces (y la de Ahora), México: Editorial Polis, 1937. 
Revolución de Carranza, hasta Tannenbaum, el precursor de la historia mexicanista en los Estados Unidos, quien en unos de sus libros - a nuestro juicio el de mayor significación - se refiere en concreto a la "Revolución Agraria."21

Este concepto tiene quizá su representación más reciente en la obra de Arnaldo Córdova, ${ }^{22}$ quien dedica un capítulo por separado a la llamada "otra revolución", refiriéndose a la social como ajena al movimiento político, que lucha por el control del poder. Se trata sin duda de una nueva tendencia en la conceptuación y por ende de la propia periodización de nuestra historia contemporánea, partiendo de la premisa de que existieron varios movimientos revolucionarios, paralelos mas no convergentes.

Las nuevas generaciones de historiadores, ajenos o siquiera afectados al mínimo por los partidismos políticos y objetivos oficiales, han empezado a definir la historia mexicana del presente siglo de manera distinta. Asi Luis González y el grupo que compiló los tres importantísimos volúmenes de las Fuentes de la historia contemporanea de México. ${ }^{23}$ Se nos recuerda aqui que ya Daniel Cosío Villegas habia incluído el porfiriato dentro del período comprendido entre 1876 y 1911 , por lo que ellos se habian abocado a la tarea de recopilar el material de lo que eventualmente deberían constituir las fuentes de la historia contemporánea, y ya no simple historia de la Revolución. Este proyecto partía del año de 1910 y llegaría hasta 1940. Es cierto, sin embargo, que gran parte del material incluído se refiere a la Revolución, dentro de los capítulos concretos que se crearon a tal efecto.

El complemento a este trabajo bibliográfico, la labor de hemerografía que bajo la dirección de Stanley Ross publicó sus Fuentes de la historia contemporánea de México. Periódicos y Revistas, ${ }^{24}$ al igual que en la obra anterior, se propuso abarcar las primeras tres décadas. Advertían al respecto: "Al principio de la investigación se redactó una lista de categorías que cubría la historia mexicana desde 1892, durante el período de Díaz, hasta 1940. El énfasis fue cronológico $y$ las divisiones correspondientes cercanamente a la secuencia de las administraciones políticas. Cada categoría se subdividió a base de tópicos. ..."25

${ }^{21}$ Frank Tannenbaum, The Mexican Agrarian Revolution, Washington, D.C.; The Brookings Institution, 1930.

${ }^{22}$ Arnaldo Córdova, La ideología de la Revolución Mexicana: Formación del nuevo régimen, México; Ediciones Era, 1937.

${ }^{23}$ Luis González et. al., Fuentes de la historia contemporánea de México: Libros y folletos, 3 vols., México: El Colegio de México, 1961-1962.

${ }^{24}$ Stanley Ross et al., Fuentes de la historia contemporánea de México: Periódicos y Revistas, 2 vols., México: El Colegio de México, 1965-1967.

${ }^{25}$ Ibid., I, 1. 
Así el trabajo quedó dividido en una serie de apartados que cubrian hasta el último año del gobierno cardenista, con un añadido de análisis de la Revolución y otro que se denominó miscelánea. Aunque sabemos que el equipo que realize esta hemerografía pretende publicar todavía dos volúmenes, se comprende que su centro o núcleo de interés se limita al año de 1940.

En ambos casos, al idear obras auxiliares para los investigadores, se observa ya un interés por no encasillar la Revolución en un contexto de cuatro décadas. Esto es: a diferencia de la sínteis, a las que hemos hecho referencia, hay ahora un intento clarísimo por entender la historia contemporánea mexicana en su contexto cronológico del siglo XX, del cual sin duda forma parte la Revolución Mexicana, pero sin abarcarlo en su totalidad.

De una u otra forma, la producción histórica ha ido en aumento constante $y$ creciente, tanto en cantidad como en calidad, dando por resultado una vasta producción de tipo monográfico, la cual debería por sí misma aportar su propia periodización.

Desde la obra de Sotelo Inclán ${ }^{26}$ hasta el magistral esfuerzo, más de dos décadas después, de John Womack, ${ }^{27}$ de historiar el zapatismo, la Revolución aparece como un marco de trasfondo histórico al tema concreto y por ende se creará su propio criterio de periodización, circunscrita a la lucha sureña.

Los ejemplos son variadísimos: ya en Ross con Madero, ${ }^{28}$ en Meyer con Huerta ${ }^{29}$ o en Tzvi Medin con Cárdenas, ${ }^{30}$ la historia de la Revolución aparece como marco de referencia, y con toda justificación, el tiempo histórico se delimita por el propio interés de la investigación.

Queremos a modo de complemento, mencionar tan sólo de paso el caso de la monografía regional. Creemos que también en este campo se presentan periodizaciones concretas y particulares. Quizá el mejor ejemplo del que podamos echar mano es el del Pueblo en Vilo ${ }^{31}$ de Luis González. Para él el periodo comprendido entre 1910 a 1924 corresponde a la Revolución, como movimiento armado. El que va de 1925 a 1932 es la Revolución Cristera; y más tarde viene la liamada Revolución Agraria, de 1933 a 1943.

${ }^{26}$ Jesús Sotelo Inclán, Raíz y Razón de Zapata: Anenecuilco, México: Editorial Etnos, 1943.

${ }^{27}$ John Womack, Jr., Zapata and the Mexican Revolution, New York: Alfred A. Knopf, 1969.

${ }^{28}$ Stanley R. Ross, Francisco I. Madero, Apostle of Mexican Democracy, New York: Columbia University Press, 1955.

${ }^{29}$ Michael C. Meyer, Huerta: A Political Portrait, Lincoln: University of Nebraska Press, 1972.

${ }^{30}$ Tzvi Medin, Ideologia y praxis politica de Lázaro Cárdenas, México: Siglo XXI Editores, 1972.

${ }^{31}$ Luis González, Pueblo en Vilo: Microhistoria de San José de Gracia, México: El Colegio de México, 1968. 
Los años comprendidos entre 1943 a 1956, los define como de Retiro y Expansión, para concluir con su "De ayer a hoy" (1957 a 1967), que nos da una connotación de proximidad. Es significativo que esta obra, como dice su autor, pretenda, ser una defensa a la historia parroquial sin limitarse o circunscribirse al período tradicionalmente aceptado; ocupándose entonces de épocas más recientes y aceptando el reto analítico actual con los peligros interpretativos que ello pudiera significar.

En años recientes, el binomio conceptual de historia mexicana contemporánea y de Revolución ha empezado a divorciarse. Así, Edmundo Flores en su Vieja revolución, nuevos problemas, ${ }^{32}$ vuelve a ocuparse de la perspectiva de vejez y anacronía de la Revolución. Aunque acepta que ésta cubre la primera parte del siglo hasta el final del gobierno de Cárdenas en 1940, reconoce igualmente que la Revolución sufre un desdoblamiento. A saber: primero una etapa armada y luego la del control político.

Nuevas perspectivas se plantean en los ensayos evaluativos de la política mexicana y ello permite ver otras posibilidades. Para Daniel Cosío Villegas, el movimiento revolucionario, iniciado en 1910 con "un levantamiento militar de revolución, sólo concluye en 1929." ${ }^{33}$ Esto hace suponer que a partir de 1929 se inicia ya una nueva etapa política y, por ende, un cambio en la perspectiva y los conceptos de periodización.

Quizá uno de los intentos mejor logrados por periodizar en su totalidad la historia contemporánea de nuestro país sea la de James W. Wilkie. Considera que los períodos ideológicos de la revolución política (enfatizando los cambios en las formas administrativas), revolución económica y revolución integral, pueden ser cuantitivamente incluidos en cuatro lapsos cronológicos: $1910-1930,1930-1940,1940-1960 \mathrm{y}$ desde $1960 .^{34}$ Importa señalar que Wilkie habla de diferentes tipos de revolución política hasta el de revolución integral, y participa así del mismo concepto admitido hasta la fecha de una revolución prolongada por más de cincuenta años. Habremos de exponer sin embargo, que Wilkie se refiere en realidad a la historia contemporánea mexicana más que al mero concepto teórico de revolución, que no cabria dentro de dicha periodización cronológica, ni en la óptica idealista ni en la marxista.

En el panorama general de la historiografía sobre el tema, merece por último una mención aparte la obra conjunta realizada por los politólogos. Sin atenernos a fechas de publicación, podríamos partir del concepto de Pablo

${ }^{32}$ Edmundo Flores, Vieja Revolución, nuevos problemas, México: Editorial Joaquín Mortiz, 1970.

${ }^{33}$ Daniel Cosío Villegas, El sistema político mexicano: Las posibilidades de cambio, México: Editorial Joaquín Mortiz, 1973.

${ }^{34}$ James W. Wilkie, The Mexican Revolution: Federal Expenditure and Social Change since 1910, 2d. ed., Berkeley and Los Angeles, University of California Press, 1970. p. 38 . 
González Casanova, quien advierte que el movimiento revolucionario iniciado en 1910 "una y otra vez, lucha por salir del eterno retorno y alcanzar sus metas." 35 El concepto de retorno aparece como de retroceso, y entonces la idea de revolución pierde toda su vigencia.

Los politólogos norteamericanos se han ocupado del tema con amplitud. En su mayoria aceptan el patrón de una Revolución iniciada en 1910 y perpetuada hasta finales del gobierno de Cárdenas. Sin embargo hay variaciones en la conceptuación evolutiva del proceso $\mathrm{y}$ así Scott, ${ }^{36}$ por ejemplo, nos dice que México ha implantado un sistema que básicamente mejora desde 1910. O sea que el país está en constante transición.

Brandenburg, ${ }^{37}$ por otra parte, entiende la Revolución como movimiento que produjo una familia de hombres visionarios que llevaron a México a una posición ejemplar entre las naciones latinoamericanas. Reune, pues, la idea de que hemos vivido por más de cincuenta años una etapa revolucionaria.

Toda esta disgregación sobre lo que se ha hecho en la historia contemporánea con respecto al concepto de periodización nos lleva irremediablemente a la vieja pregunta de si estamos ya en condiciones que nos permitan formular una nueva periodización; cosa que sólo puede comprenderse en un intento por entender la historia moderna de México de manera integral. Habría que aceptar, desde luego, que subsisten períodos y temas poco estudiados, aunque los trabajos monográficos individuales hayan cubierto ya una gran cantidad de los mismos.

Sin embargo en el intento de idear una nueva periodización, habría que preguntarse por la utilidad de la misma y la posibilidad de que precisamente a través de ella puedan estudiarse las etapas no estudiadas, las ignoradas e, incluso, atreverse a revisar los análisis existentes sobre otros períodos.

Sabemos que nuestro país, $\tan$ abocado desde el siglo XIX a la historia política, ha descuidado la económica y la social. Sería quizá positivo tratar de estudiar los cambios económicos del presente siglo con mayor rigor metodológico marxista. Nos preocupa saber dónde quedó la historia del pueblo, de las masas arrastradas a la lucha revolucionaria. Qué se hizo de ellos, qué se les dió, o qué tomaron; si hubo cambios o transformaciones posteriores. Qué es de ellos hoy día. Qué pasó con el campesino común, a quién se le entregaron tierras; qué pasó con los campesinos sin tierras que incluso durante el movimiento cristero se fueron a luchar con la esperanza y supuesta promesa de obtenerlas, etc.

${ }^{35}$ Pablo González Casanova, La democracia en México, México: Ediciones Era, 1969, p. 11.

${ }^{36} \mathrm{Cf}$. Robert E. Scott, Mexican Government in Transition, Urbana: University of Illinois Press, 1959.

${ }^{37}$ Cf. Frank Brandenburg, The Making of Modern Mexico, Englewood Cliffs, N.J., Prentice-Hall, 1964. 
Es indudable que, de acuerdo con los intereses específicos del historiador, la historia contemporánea de México buscará y se acomodará a una periodización idónea. En efecto: el historiador centrado en el proceso diplomático, por ejemplo, tendrá que hacer una división diferente de su tiempo histórico, del que pretenda hacer una historia monográfica o del que se proponga una investigación a nivel regional.

Aceptando a priori la existencia de grandes períodos poco o nada estudiados para ponernos a periodizarlos habría que definir, por último, si la historia contemporánea de México es tan sólo la historia de la Revolución o si ésta realmente concluyó con el final de la segunda década o persistió hasta 1940. Surge entonces una posibilidad dialéctica en torno a los valores que deben tomarse en cuenta. ¿Debemos partir de las acciones de armas; de los triunfos militares o políticos; de los planes y manifiestos políticos; de las demandas de reivindicación social o de los cambios de estructuras económicas?

Ya Toynbee decia que antes de periodizar debemos reconstruir las faces principales en la historia de las civilizaciones: nacimiento, crecimiento, dislocación y decadencia; porque sólo esto permitiría distinguir las experiencias comunes de las individuales, permitiendo un programa historiológico comparativo. En este caso se concede a la historia la posibilidad de saltos, para pasar de una sociedad primitiva a otra evolucionada o civilizada.

En fin, más que diseñar o inventar una nueva periodización, es posible que a fuerza de analizar las ya existentes sólo podamos proponer una remodelación de la misma.

Aceptamos entre otras muchas deficiencias que la historia nacional, en gran número de casos, se presenta como una historia aislada y subjetiva. Por ello suponemos que la nueva periodización no debería olvidarse de encuadrar a México en el contexto universal.

No podemos ya pensar siquiera en una periodización particular, desligada de la historia de México, sin recurrir al mundo exterior: la América Latina, los cambios universales, etc.

Tampoco puede la tradicional periodización política olvidarse, por ejemplo, del factor sine qua non de nuestra historia independiente: el del control y manipulación del poder, temática de interés común entre los historiadores mexicanistas. Unido a ésto, habría que completar el estudio de los sistemas, instituciones y agencias gubernamentales, ver cómo funcionan y no sólo cómo se desarrollan.

Consideramos, pues, que una posible periodización podría iniciarse, para la historia contemporánea de México, con la decadencia del porfiriato. A saber: una primera etapa que vaya de 1904 hasta la muerte de Madero en 1913. Esta etapa de antecedentes, precursora de la Revolución, podría incluir el análisis cualitativo de la caducidad de las instituciones gerontocráticas del porfiriato; su desmantelamiento. El surgimiento de los primeros grupos ideológicos de 
oposición; sin olvidar, claro está, los movimientos clandestinos de campesinos y obreros y las causas de tipo económico, como la crisis de 1907, que influyeron de manera definitiva en el giro de la historia nacional.

Vendría luego un período, el de la Revolución propiamente dicha. Esto es: de 1913 a 1917, incluyendo las facetas tanto de la lucha armada por el control político, como el surgimiento de una conciencia de lucha social, representada a su vez tanto por la "revolución de Zapata" (que pretende la justicia social mediante la redistribución de la tierra entre los despojados), como por la "revolución de Villa" (que busca dotar de tierras a los desarraigados). Bien puede argumentarse, por ejemplo, que Zapata se había levantado en armas tiempo atrás. Pero suponemos que la lucha a un nivel revolucionario abarca diferentes enfoques y participaciones, pero se generalizó en su totalidad nacional con la muerte de Madero y la instauración del huertismo, que incluso si no hubiese servido para nada, al menos logró unificar al país en su contra, haciendo posible el inicio de la Revolución, a nivel y categoría nacionales.

Con la proclamación de la nueva constitución, en 1917, se inicia a nuestro juicio un nuevo período, que si bien no pertenece ya a la Revolución propiamente dicha, constituye una etapa que podriamos definir como de "caudillismo post-revolucionario." Esto es: los gobiernos emanados de la lucha por el control político en sus diferentes facetas: carrancismo, grupo sonorense, rebelión delahuertista, hasta la muerte de Obregón en 1928. Epoca en la cual surge un nuevo dinamismo de las clases sociales, al implantarse de hecho los postulados de la Constitución de 1917; generando simultáneamente, sobre todo en la época comprendida entre 1924 a 1928, un caudillismo o autoritarismo. Años en que se operan los grandes cambios en juego de ajedrez, que llevan al maestro de este juego político, Calles, a crear $s u$ sistema de gobierno.

Otro reagrupamiento histórico incluiría los años de 1928 hasta 1935. El maximato, para usar el viejo término. Período en que el caudillismo se neutraliza mediante la creación del Partido Nacional Revolucionario, con el cual, como dice Córdova, "la posibilidades de explosiones revolucionarias de las masas populares se conjura permanentemente con el programa de reformas sociales y se desprestigia en continuación en el seno de las propias masas, toda oposición revolucionaria, política o ideológica que ésta sea, (principalmente por lo que toca a los movimientos políticos marxistas), aduciendo la imagen del Estado que se debe al pueblo, a los trabajadores y que lucha contra una "reacción," (abstracta, intangible), que en ningún momento deja de amenazar las "conquistas" de la Revolución. ${ }^{38}$

Surge, pues, un concepto institucionalizado de Revolución, dándosele por

${ }^{38}$ Córdova, La ideologia, p. 36. 
consecuencia un carácter sólido y monolítico al poder. Ello, claro, no ha impedido que nuestro país haya continuado cultivando el mito popular de la idea de continuidad revolucionaria. Todo programa de reforma, nacionalización y hasta expropiación se hará en nombre de la santificada Revolución.

Este período del Maximato, insistimos, no termina sino hasta 1935, cuando de hecho Cárdenas se sacude la tutela callista e inicia su gobierno, para dar quizá el caso singular de un período lleno de particularidades en su derredor. Así, la que va de 1935 a 1940 podemos considerala como una etapa que podría definirse como rescatadora de los propósitos, los valores e incluso la ideología misma de la Revolución. Trata sin duda de llevar a efecto muchos cambios, especialmente en el orden social. En su actitud surge la perspectiva de un cambio, de una etapa diferente, a la que alguna vez Trotsky se refiriera como el bonapartismo mexicano, donde el papel central está representado por el líder carismático que impone relaciones personalistas permanentes.

La siguiente etapa, inaugurada con el gobierno de Manuel Avila Camacho, bien puede extenderse de 1940 hasta 1968.

Sin duda la segunda conflagración mundial vino a cambiar también, entre muchas otras cosas, nuestros conceptos históricos nacionales. Empezó una época de estabilidad. La lucha de caudillos y de caciques había quedado atrás, dando paso a lo que con todo acierto Moisés González Navarro ha definido como "El orto de la sociedad industrial." 39 Puede decirse que el proceso evolutivo nacional, a partir de esta época, tiene distintos matices dentro de una misma armonía. Pertenece a este período el viraje hacia el civilismo y el cambio que en sí significó el paso del poder a manos de hombres que no habían participado en la lucha armada. Fue entonces también cuando se incubó y desarrolló lo que nuestros economistas han definido como "el milagro mexicano." ${ }^{40}$ Los viejos revolucionarios y los nuevos gobernantes, reunidos todos en el PRI, propician con el impartidismo la estabilidad nacional. Se acepta oficialmente que la Revolución se ha institucionalizado. $\mathrm{Ni}$ la falta de apoyo cardenista a la selección de Alemán, para llevar a Casas Alemán a la primera magistratura, ni el triunfo de Ruiz Cortines, ni la propia e inusitada lucha electoral del general Henríquez Guzmán, harán variar esta situación. Ni la sutil pugna política generada entre alemanistas y cardenistas puso en peligro el sólido edificio político construido por el ahora ya viejo orden de los revolucionarios. Quizá fue en el conflicto ferrocarrilero de 1959 cuando esta solidez presentó las primeras pruebas de resquebrajamiento.

$\mathrm{El}$ año de 1968 marca, a nuestro juicio, el verdadero cambio en el proceso

${ }^{39}$ Moisés González Navarro, La Confederación Nacional Campesina: Un grupo de presión en la Reforma agraria Mexicana, México: Costa Amic, 1968, p. 185.

${ }^{40}$ Cf. Fernando Carmona et al., El Milagro Mexicano, México: Editorial Nuestro Tiempo, 1971. 
evolutivo nacional. Al fin esas instituciones que parecían ya agotadas se sacudieron con el movimiento estudiantil, que culminó con la matanza de Tlatelolco. Surgieron muchas hipótesis explicativas al respecto, conceptos antagónicos a veces; pero sin lugar a dudas, tanto los representantes del gobierno como sus más enconados críticos concuerdan en señalar que esta fecha establece un nuevo período dentro de la historia contemporánea de México.

Uno de los termómetros más útiles para medir el impacto que tuvo dicho movimiento lo tenemos en el propio Partido Revolucionario Institucional, que luego de 1968 ha buscado un reajuste, un reacomodo e incluso quizá una reforma interna en su propósito por revalorar sus fundamentos, sus metas, sus realidades.

Es difícil pronosticar hasta cuándo se extenderá esta nueva etapa de la historia moderna de México. Habrá que aceptar, sin embargo, que la historia mexicana del presente siglo tiene un hecho que, lo mismo en su acontecer histórico como en su narración y evaluación historiadas, representa una encrucijada clave para conocer y analizar nuestra realidad mexicana.

Un hecho importantísimo pero no único, ni inmóvil, ni sagrado. En suma, un hecho temporal: histórico e historiable. 